\title{
Australian dental students views on a compulsory internship scheme
}

Ratilal Lalloo ${ }^{a}$, Newell W Johnson ${ }^{\mathrm{b}}$, Anthony Blinkhorn ${ }^{\mathrm{c}}$ and Paul Ichim

${ }^{\mathrm{a}}$ School of Dentistry \& Oral Health and Griffith Health Institute, Griffith University, Australia

${ }^{\mathrm{b}}$ Griffith Health Institute, Griffith University, Australia

${ }^{\mathrm{c}}$ Faculty of Dentistry University of Sydney, Australia

${ }^{\mathrm{d}}$ School of Dentistry, Oral Health Centre of WA, University of Western Australia, Australia

\section{Correspondence to:}

Ratilal Lalloo, Colgate Chair: Rural, Remote and Indigenous Oral Health, DOH, Gold Coast campus, Griffith University, QLD, 4222.

E-mail: r.lalloo@griffith.edu.au 


\begin{abstract}
Objective: The National Health and Hospitals Reform Commission Report suggests introducing an internship period for all newly qualified dental/oral health practitioners in Australia. This study gauged the opinions of undergraduates from three dental schools in Australia.
\end{abstract}

Methods: An online survey collecting demographic information on gender and age, the program registered for, year and place of study. The level of support for an internship was gauged using a 5-point scale. Open-ended questions on the concerns, advantages and disadvantages of an internship concluded the survey. All students in the participating universities were invited to participate via e-mail.

Results: There were 445 responses. $40 \%$ of students were supportive of an internship scheme. The level of support differed by gender, age, relationship status, having a previous tertiary qualification and year of study. Males, older participants, those with children and those with previous qualifications were less supportive. The main concerns related to issues around choice, family commitments, location of internship placements and salary levels.

Conclusion: Support for an internship scheme for dental graduates elicited a divided opinion amongst dental students. Many issues around financing and logistics have to be addressed before any such scheme could be implemented in Australia: there is a need to consult with dental graduates and promote the benefits to the student body.

\title{
Keywords
}

internship, students, health reforms, access, dental education 


\section{Introduction}

Access to dental care in Australia is difficult for many people, especially in rural, remote and/or Indigenous communities ${ }^{1,}{ }^{2}$. Reasons include maldistribution of clinicians, ${ }^{3}$ under-funding of public services and high costs of private dentistry ${ }^{1,4}$. An editorial on access to oral health care in the Australian Medical Journal ${ }^{2}$ concluded with the following statement: "Currently, patients with acute oral conditions should hope that the problem occurs during normal hours in a major population centre, that the condition is not part of a larger problem, and that they are wealthy enough to have a regular dentist who has the time to see them."

The Government of the Commonwealth of Australia is concerned about equitable access to health care for all Australians, and the provision of an adequate workforce to meet the needs of the whole population. The Labour Government took office on 3 December 2007 and immediately commissioned a major review. The final Report of the National Health and Hospitals Reform Commission was published in June $2009^{1}$. This summarises the many issues confronting dentistry in Australia. Four recommendations germane to oral health were made: (1) 'Denticare Australia' which is designed to provide universal, regular basic dental care to adults. (2) A one-year internship scheme prior to full registration for all new dental and oral health therapy graduates, which is aimed at providing significantly more public and rural dental services and expanding the dental workforce's experience and interest in serving people and groups with special needs. (3) National expansion of the pre-school and school dental programs, aimed at ensuring universal, regular oral health care for children. (4) 
Additional funding for improved oral health promotion to facilitate a greater focus on the prevention of oral disease.

Much work remains to be done concerning the details around these recommendations, not only including funding and management, but also their acceptability to both the public and the health care professions. This study is focussed on the second recommendation: the possible introduction of an internship scheme. The Australian Dental Association has submitted a proposal supporting the scheme and has further attempted to detail the issues that need to be addressed for this undertaking. ${ }^{5}$ The attitudes of current students should be useful in gauging the acceptability of an internship to future graduates as this could only be required of students, if they aware of it prior to registering for their program, unless it is voluntary. The aim of the study was to record the opinions of 2009 dental undergraduates from three dental schools in Australia. The information gathered from this survey will inform the debate on the introduction of an internship period for newly qualified oral health practitioners prior to full registration. 


\section{Methods}

The dental schools at Griffith University (GU), the University of Western Australia (UWA) and the University of Sydney (Sydney) participated. An online survey instrument was developed (www.SurveyMonkey.com) to collect demographic information on gender and age, as well as the degree program, year and place of study. The level of support for an internship was gauged using a 5-point scale, ranging from very supportive to very unsupportive. Opinions were further assessed on the length and location of internships. Open-ended questions on the concerns, advantages and disadvantages of an internship were included.

All students were invited to participate via e-mail. The e-mail address used was that on the training institution's database. The survey was anonymous and voluntary. All responses were secured online and downloaded via the Web to the researcher's computer for statistical analysis. In this paper the findings of the quantitative aspects of the survey are presented and the qualitative (open-ended questions) are explored. The quotes presented are reported as submitted by the participant.

This study was approved by the Griffith University Human Research Ethics Committee (GU Ref No: DOH/11/09/HREC). 


\section{Results}

A total of 445 students responded, a response rate of close to 50\%. Table 1 summarises the characteristics of the respondents. There were slightly more female respondents (56.2\%), more than two-thirds (70.8\%) were younger than 24 years of age, and half (51.0\%) were from years 1 and 2 of their degree program.

Less than half (40.2\%) of the respondents were supportive of an internship period (Table 2). The level of support differed by gender, age, relationship status as well as whether they had a previous tertiary qualification and current year of study. More females (43.6\%) were supportive of the scheme compared to males (25.5\%). Almost a half (46.7\%) of students younger than 22 years of age were supportive compared to a third (33.6\%) of students older than 24 years. A quarter of respondents with children (either in a relationship or single) were supportive, compared to almost $44.5 \%$ who were in a relationship with no children and $39.4 \%$ of those single with no children. Just more than a third (35.8\%) of students with a previous tertiary qualification supported the scheme compared to $45 \%$ amongst those with no previous tertiary qualification. Students in their earlier years $\left(1^{\text {st }}\right.$ and $\left.2^{\text {nd }}\right)$ of the program were less supportive than senior students (Table 2). Opinions also differed by university but this is more related to the graduate entry requirement and the age distribution of students. Sydney students need a tertiary qualification for entry into dentistry. A quarter of GU and $12 \%$ of UWA students had a previous tertiary qualification. Overall the mean age of Sydney respondents was 25 years compared to 22 and 21 years at GU and UWA respectively. Less than half (46.6\%) were willing to be placed in rural and remote settings. Almost all students equally preferred a 6-month or 1-year internship period. 
The main concerns related to issues around choice, family commitments, location of internship placements and salary levels.

"Logistical problems of moving to a different place with a partner who's situation may not allow them to also move. Unable to live near family. Living in a rural community where it is difficult to make new friends due to there being less people that we can relate to and become close friends with (eg, young people, tertiary educated, etc)."

"Ability to support myself in rural areas (rent and etc) and dealing with the people and the community in unfamiliar environment."

The advantages of an internship period mainly related to the experience that an internship would offer, time to further develop clinical skills, providing health care to patients from remote and rural settings.

"The opportunity to hone clinical experience which may not have been attained to an ideal level during study (due to lack of patients/procedures). Guaranteed payed employment directly following graduation. The opportunity to provide assistance to communities who do no usually benefit from access to appropriate and timely dental care The provision of continuous supervision during the first year. Following graduation to hone clinical and interpersonal skills before entering the work force proper.”

"More supervised clinical experience means you are able to make more accurate diagnosis, treatment planning and provide better treatment, whilst gaining more experience as a whole before being an independent dentist. It will also increase the clinician's confidence in all aspects of clinical dentistry and patient management, which I believe is essential in this field."

The disadvantages expressed mainly related to poor salaries, the additional time prior to being able to enter the private sector and being away from family. 
"People have to deal with low salary which is highly unfair to the graduating dentist as they already possess adequate skills to perform their work due to the extensive practical component within their study. Internship is unnecessary as graduating dentist already has plenty of hands on experience to qualify as a fully accredited dentist unlike medical students.”

"The disadvantage would be that for students who have loans and debts, it would be impossible to start paying off their loans on a salary thats below the starting salary of current 1st year outs. An internship that doesn't expose us to a variety of settings and different aspects of dentistry could be almost useless.” 


\section{Discussion}

The internship proposal, while it has many laudable benefits, still needs substantial effort in planning its implementation. There are numerous financial, infrastructure, management and logistical issues that need to be addressed, and this paper will not attempt to discuss these in any detail. Rather we attempt to explain the findings emanating from this study. The opinion of the current dental undergraduates on this proposed scheme is divided, almost down the middle. The level of support is fairly good considering that the benefits of the scheme are yet to be promoted. The level of support is however not surprising, in that elsewhere when similar schemes were mooted, support amongst stakeholders was low. For example a 1-year community service (similar to the internship scheme suggested here) was implemented about a decade ago in South Africa, and after initial resistance from various stakeholders, including dental students, it now appears to be a highly successful scheme and support has significantly improved over time as initial implementation issues were resolved ${ }^{6-9}$. Investigations of the vocational training scheme in the United Kingdom have highlighted both the positive and negatives of such a scheme over the many years since its implementation ${ }^{10-}$

12. The experiences of these countries and elsewhere is important to assess as an Australian policy is investigated and considered.

Factors influencing the level of support for an internship period mainly relate to whether student had a previous tertiary qualification, the age of students and year of study, relationship status, and these are all inter-related. Those with a previous tertiary qualification were less supportive compared to respondents who entered the dental program without one (most straight from school and fewer with work experience). 
Those with a previous qualification are older when they enter the program, and therefore may be under greater pressure to start earning a higher salary, to pay back loans that have accumulated over many years of tertiary education. Being older they may have family obligations that drive the financial imperative and makes relocating and being away from home less attractive. A number of dental schools in Australia are graduate entry and others are considering the same entry requirement. This study suggests that this is likely to reduce levels of support for a scheme that lengthens the time to full registration. Respondents in the junior years of their dental course were also less supportive compared to senior students. Junior students may not as yet appreciate the benefits of an internship period post graduation and may feel an additional year prior to employment problematic.

The quality of applicants for dental courses may be compromised if an internship is introduced without addressing the possible concerns of potential applicants regarding such a scheme. Students with previous tertiary qualification may opt for other courses that do not entail an additional year prior to full registration.

A commonly expressed concern relates to the availability of supervisors and mentors. Respondents were concerned about being placed in settings that lacked adequate availability of a supervisor and/or mentor, and this is most likely to occur in rural and remote settings. It would therefore be unfair (and perhaps even unethical) to place new graduates in these communities with no experienced supervisor. There is therefore an urgent need to not only develop the infrastructure in rural and remote communities but also to build a cadre of oral health personnel with supervisory and mentorship 
capabilities $^{13}$. It may also be imperative that dental schools provide a varied (including a rural, remote and Indigenous) clinical experience during the undergraduate course so that new graduates are not confronted by an unfamiliar setting for the first time during the internship. The three dental schools participating in the study offer their dental/oral health students a rural and remote clinical experience, it being compulsory at GU and UWA and voluntary at Sydney. These rural experiences are highly appreciated by the students and the educational and public health values are illustrated in the feedback from students ${ }^{14,15}$.

New oral graduates and the community will be the principal beneficiaries of an internship scheme. The benefits of such a scheme need to be identified and promoted to all stakeholders. Increasing the acceptance of such a scheme would accelerate the much needed political and financial support.

Support for an internship scheme for dental graduates elicited a divided opinion amongst dental students. Addressing the concerns of current and future dental students and promoting the benefits of the scheme needs to be an important aspect of the implementation plan. 


\section{References}

1. National Health and Hospitals Reform Commission. A Healthier Future For All Australians. Barton, ACT: Commonwealth of Australia; 2009.

2. Marshall RI, Spencer AJ. Accessing oral health care in Australia. Medical Journal of Australia, 2006; 185: 59-60.

3. Australian dentist labour force 2003. Australian Dental Journal, 2006; 51; 191-194.

4. AIHW Dental Statistics and Research Unit. Economic aspects of dentistry. Adelaide, ARCPOH, University of Adelaide, 2004.

5. Australian Dental Association. Proposal for a National Dental Foundation Year Program. Sydney: Australian Dental Association, 2009.

6. Naidoo S, Chikte U. Community dental service--the first year. South African Dental Journal, 2002; 57: 193-196.

7. Naidoo S. Community dental service--four years on. South African Dental Journal, 2007; 62: 250, 252-253.

8. Bhayat A, Yengopal V, Rudolph MJ, Naidoo U, Vayej A. Attitudes of South African oral hygienists towards compulsory community service. International Journal of Dental Hygiene, 2008; 6: 8-12.

9. Bhayat A, Yengopal V, Rudolph MJ, Govender U. Attitudes of South African dental therapy students toward compulsory community service. Journal of Dental Education, 2008; 72: 1135-1141.

10. Bonetti D, Young L, Rennie J, Clarkson J. Evaluating dental vocational training: how does Scotland compare to the rest of the UK? British Dental Journal, 2008; 204: 195-202.

11. Levine RS. Experience, skill and knowledge gained by newly qualified dentists during their first year of general practice. British Dental Journal, 1992; 172: 97-102.

12. Bartlett DW, Coward PY, Wilson R, Goodsman D, Darby J. Experiences and perceptions of vocational training reported by the 1999 cohort of vocational dental practitioners and their trainers in England and Wales. British Dental Journal, 2001; 191: 265-270.

13. Cabot LB, Patel HM, Kinchin IM. Dental vocational training: identifying and developing trainer expertise. British Dental Journal, 2007; 203: 339-345.

14. Bazen JJ, Kruger E, Dyson K, Tennant M. An innovation in Australian dental education: rural, remote and Indigenous pre-graduation placements. Rural Remote Health, 2007; 7: 703.

15. Lalloo R. What is best about the Rural, Remote \& Indigenous Oral Health Dental Clinic placement in Brewarrina, NSW? A students' perspective. Brisbane: ADAQ News; 2009. 
Table 1: Characteristics of respondents $(\mathrm{N}=445)$

\begin{tabular}{|c|c|c|}
\hline Characteristic & Number $\dagger$ & Percentage \\
\hline \multicolumn{3}{|l|}{ Gender: } \\
\hline Female & 250 & 56.2 \\
\hline Male & 194 & 43.6 \\
\hline \multicolumn{3}{|l|}{ Age group: } \\
\hline$<22$ years of age & 165 & 37.8 \\
\hline $22-24$ years of age & 144 & 33.0 \\
\hline$>24$ years of age & 128 & 29.3 \\
\hline \multicolumn{3}{|l|}{ Relationship status: } \\
\hline In relationship or single with children & 24 & 5.4 \\
\hline In relationship with no children & 137 & 30.8 \\
\hline Single with no children & 282 & 63.4 \\
\hline \multicolumn{3}{|l|}{ State: } \\
\hline NSW & 177 & 39.8 \\
\hline QLD & 75 & 16.9 \\
\hline WA & 88 & 19.8 \\
\hline Other & 41 & 9.3 \\
\hline Overseas & 63 & 14.2 \\
\hline \multicolumn{3}{|l|}{ Previous tertiary qualification: } \\
\hline Yes & 226 & 50.9 \\
\hline \multicolumn{3}{|l|}{ Current vear of study: } \\
\hline $1^{\text {st }}$ & 110 & 24.7 \\
\hline $2^{\text {nd }}$ & 117 & 26.3 \\
\hline $3^{\text {rd }}$ & 103 & 23.1 \\
\hline $4^{\text {th }}$ & 68 & 15.3 \\
\hline $5^{\text {th }}$ & 47 & 10.6 \\
\hline \multicolumn{3}{|l|}{ Institution: } \\
\hline Griffith University & 151 & 33.9 \\
\hline Sydney University & 179 & 40.2 \\
\hline University of Western Australia & 112 & 25.2 \\
\hline
\end{tabular}

$\dagger$ numbers occasionally add up to less than 445 due to missing data 
Table 2: Level of support for an internship period (\%) $\dagger$

\begin{tabular}{lccccc}
\hline & $\begin{array}{c}\text { Very } \\
\text { supportive }\end{array}$ & Supportive & Unsupportive & $\begin{array}{c}\text { Very } \\
\text { unsupportive }\end{array}$ & $\begin{array}{c}\text { Not } \\
\text { sure }\end{array}$ \\
\hline Overall & 12.1 & 28.1 & 20.9 & 29.2 & 9.4 \\
\hline Gender: & & & & & \\
Female & 10.4 & 33.2 & 20.0 & 25.6 & 10.4 \\
Male & 14.4 & 21.1 & 22.2 & 34.0 & 8.2 \\
\hline Age group: & & & & & \\
$<$ 22 years & 11.5 & 35.2 & 20.6 & 22.4 & 10.3 \\
22-24 years & 9.7 & 27.8 & 20.1 & 31.3 & 10.4 \\
> 24 years & 14.8 & 18.8 & 22.7 & 35.9 & 7.8 \\
\hline Relationship status: & & & & & \\
In relationship or & & & & & \\
single with children & 12.5 & 12.5 & 33.3 & 37.5 & 4.2 \\
In relationship with & & & & & \\
no children & 14.6 & 29.9 & 15.3 & 31.4 & 8.8 \\
Single no children & 11.0 & 28.4 & 22.7 & 27.3 & 10.3 \\
\hline Previous tertiary qualification: & & & & \\
Yes & 13.7 & 22.1 & 16.4 & 40.7 & 7.1 \\
No & 10.6 & 34.4 & 25.2 & 17.4 & 11.9 \\
\hline Current year of study: & & & & & \\
$1^{\text {st }}$ & 10.9 & 19.1 & 19.1 & 42.7 & 8.2 \\
$2^{\text {nd }}$ & 7.7 & 21.4 & 23.9 & 40.2 & 6.8 \\
$3^{\text {rd }}$ & 13.6 & 34.0 & 22.3 & 21.4 & 8.7 \\
$4^{\text {th }}$ & 20.6 & 35.3 & 14.7 & 14.7 & 13.2 \\
$5^{\text {th }}$ & 10.6 & 42.6 & 23.4 & 8.5 & 14.9 \\
\hline
\end{tabular}

$\dagger$ Percentages may not add to $100 \%$ due to rounding and missing data 